Abstracta Iranica

Revue bibliographique pour le domaine irano-aryen

Volume 29 | 2008

Comptes rendus des publications de 2006

\title{
Farhang-e TārīH-e Beyhaqī. Tehrān, Zavvār, 1384/2005, 803 p., cartes.
}

\section{David Durand-Guédy}

\section{(2) OpenEdition}

\section{Journals}

\section{Édition électronique}

URL : http://journals.openedition.org/abstractairanica/31352

DOI : 10.4000/abstractairanica.31352

ISSN : 1961-960X

Éditeur :

CNRS (UMR 7528 Mondes iraniens et indiens), Éditions de l'IFRI

\section{Édition imprimée}

Date de publication : 15 mai 2008

ISSN : 0240-8910

\section{Référence électronique}

David Durand-Guédy, « Farhang-e Tārīh-e Beyhaqī. Tehrān, Zavvār, 1384/2005, 803 p., cartes. », Abstracta Iranica [En ligne], Volume 29 | 2008, document 326, mis en ligne le 15 septembre 2008, consulté le 26 septembre 2020. URL : http://journals.openedition.org/abstractairanica/31352 ; DOI : https://doi.org/10.4000/abstractairanica.31352

Ce document a été généré automatiquement le 26 septembre 2020.

Tous droits réservés 


\title{
Farhang-e TārīHü-e Beyhaqī. Tehrān, Zavvār, 1384/2005, 803 p., cartes.
}

\author{
David Durand-Guédy
}

1 Ce livre se veut un "handbook" destiné à faciliter la lecture du TārīH-e Beyhaqī (TB). Conçu comme un gros lexique, le livre est articulé en cinq parties. La première est une présentation de Beyhaqī et de son œuvre. On y trouve notamment des développements sur les mots et expressions persanes, ainsi que sur les mots arabes (environ 430) utilisés par Beyhaqī (cf. liste pp. 34-5). La seconde partie présente le vocabulaire technique, qui est classé en fonction du service administratif concerné (e.g. eqțā est expliqué dans la section dìvān-e estîfầ). La troisième partie est consacrée aux mots rares, aux alternances vocaliques ou consonnantiques (degargūnī-hāa-ye āvāì , e.g. heždah pour hejdah), aux mots polysémiques (e.g. dìvān), aux mots composés, aux catégories sociales et aux fonctions (e.g. šehna), aux mots d'origines étrangère (turcs, pashto, mongols, chinois - l'arabe est traité plus haut), et enfin aux hadīts et citations coraniques. La quatrième partie, qui constitue le cœur de l'ouvrage, est un lexique géographique et biographique comptant 1200 entrées. La dernière partie comprend les annexes (index des proverbes, liste dynastiques, cartes). L'A. a pris soin de comparer les différentes éditions, en particulier les deux éditions de références que sont celles de Rahbar et de Fayyāạ.

2 Il est probable que ce livre, qui comble une indéniable lacune, rendra service à ceux à qui il est en priorité destiné : les étudiants en littérature et en sciences humaines. En revanche, son intérêt pour les chercheurs amenés à utiliser le TārīH-e Beyhaqĩ est plus discutable. La présence d'un index récapitulatif, au moins pour les termes techniques que l'on retrouve intégrés dans différentes sections (e.g. rekābdār traité p. 118 et p. 126), aurait été souhaitable. La méconnaissance de l'état de la recherche sur Beyhaqī hors d'Iran est patente : les études de Waldman (1980) et Meisami (1999), pour ne citer que les plus importantes, ne sont même pas citées. Mais plus dérangeante encore est l'absence totale d'analyse dans la composition des notices de la quatrième partie. L'A. s'est contenté de compiler les diverses sources à sa disposition (DehHुodā, Mo'īn, Bartold dans sa traduction persane, etc.), mais sans chercher à isoler ce qui pourrait être pertinent pour la lecture du TB. L'entrée “Turk", par exemple, se contente de citer 
des vers de Nezāāmī, Ferdowsī, Sanā'ī. L'entrée "Ișfahān" compile différentes notices sur l'histoire de la ville jusqu'à nos jours, alors que l'on aurait préféré, bien entendu, voir comment la ville était présentée par Beyhaqī. C'est comme si l'A., doublement écrasé par l'importance de l'œuvre qu'il traitait et par les travaux des "grands anciens ", n'avait pas assumé sa condition de chercheur. Aussi, ce lexique n'est véritablement utile que pour les entrées concernant des lieux ou des personnages moins connus, à propos desquels l'A. a été obligé, sinon de produire un texte original, au moins de se référer directement à Beyhaqī. Au final, un travail monumental, mais qui laisse le lecteur souvent sur sa faim.

INDEX

Thèmes : 11.1.1. Littérature persane classique

\section{AUTEURS}

DAVID DURAND-GUÉDY

IFRI - Téhéran 